\title{
Los desafíos para las cooperativas de ahorro y préstamo de nivel básico en México*
}

The challenges for basic-level savings and loan cooperatives in Mexico

Os desafios para as cooperativas de poupança e crédito de nível básico no México

\author{
Graciela Lara-Gómez ${ }^{1}$ \\ Jesús Hurtado-Maldonado²
}

Recibido: 20 de septiembre de 2018

Aceptado: 18 de abril de 2019

Publicado: 21 de julio de 2019

Cómo citar este artículo: Lara-Gómez, G. y Hurtado-Maldonado, J. (2019). Los desafíos para las cooperativas de ahorro y préstamo de nivel básico en México. Cooperativismo \& Desarrollo, 27(2), 1-25. doi: https://doi.org/10.16925/2382-4220.2019.02.01

* $\quad$ Artículo de investigación. https://doi.org/10.16925/2382-4220.2019.02.01

1 Universidad Autónoma de Querétaro (México). ORCID: https://orcid.org/0000-0001-9984-7372. Cerro de las Campanas s/n, Col. Las Campanas, C.P. 76010 Santiago de Querétaro, Qro. México.

Correo electrónico: glara@uaq.mx; glaragomez@yahoo.com.mx

2 ORCID: https://orcid.org/0000-0002-4690-9100 


\section{Resumen}

El presente artículo aborda las problemáticas que predominan entre las cooperativas de ahorro y préstamo de nivel básico en México. Estas cooperativas son organizaciones que proporcionan servicios financieros y contribuyen con mejoras sociales en las regiones pobres, donde la banca tradicional tiene escasa o nula presencia. Se propone que la persistencia de estas organizaciones se encuentra amenazada por diversos factores, entre ellos, la escasa formalización de sus procesos de gestión y por las normas regulatorias que acotan su participación en el mercado. Se presenta una perspectiva teórica centrada en la economía social y una aproximación metodológica cualitativa, para responder a la pregunta: ¿cuáles son los desafíos que deben afrontar las cooperativas de ahorro y préstamo de nivel básico en México? Este es el punto de partida para analizar al sector y a una cooperativa ubicada en una localidad de alto rezago económico. Los resultados muestran que los desafíos a afrontarse por el sector se vinculan con la necesidad de evidenciar las desventajas de la legislación, para buscar su reforma. En la cooperativa estudiada los retos deben atenderse con visión de futuro, impulsando la continuidad de la organización a partir de estrategias que integren su doble finalidad económica y social.

Palabras clave: ahorro, cooperativas, desafíos, gestión, préstamo, regulación.

\section{Abstract}

This article addresses the predominant problems among the basic-level savings and loan cooperatives in Mexico. These cooperatives are organizations that provide financial services and contribute to social improvements in poor regions, where traditional banking has little or no presence. It is proposed that the persistence of these organizations is threatened by various factors, including the lack of formalization of their management processes and the regulatory standards that limit their participation in the market. A theoretical perspective focused on social economy and a qualitative methodological approach is presented to answer the following question: What are the challenges that basic-level savings and loan cooperatives face in Mexico? This is the starting question with which to analyze the sector and a cooperative located in a town experiencing high economic lag. The results show that the challenges to be faced by the sector are linked to the need to show the disadvantages of the legislation, in order to seek its reform. In the cooperative studied, the challenges must be addressed with a vision of the future, promoting the continuity of the organization based on strategies that integrate its dual economic and social purpose.

Keywords: savings, cooperatives, challenges, management, loans, regulation.

\section{Resumo}

Este artigo aborda as problemáticas predominantes entre as cooperativas de poupança e crédito de nível básico no México. Essas cooperativas são organizações que proporcionam serviços financeiros e contribuem com melhoras sociais nas regiões pobres, em que o sistema bancário tradicional tem escassa ou nenhuma presença. Propõe-se que a persistência dessas organizações se encontre ameaçada por diversos fatores, entre eles, a pouca formalização de seus processos de gestão, e pelas normas regulamentares que limitam sua participação no mercado. É apresentada uma perspectiva teórica centralizada na economia social e uma aproximação metodológica qualitativa para responder à pergunta: quais são os desafios que as cooperativas de poupança e crédito de nível básico no México devem enfrentar? Este é o ponto de partida para analisar o setor e uma cooperativa localizada em uma área de alto poder aquisitivo. Os resultados mostram que os desafios que o setor deve enfrentar estão vinculados à necessidade de evidenciar as desvantagens da legislação para buscar sua reforma. Na cooperativa estudada, os desafios devem ser entendidos com vistas ao futuro, impulsionando a continuidade da organização a partir de estratégias que integrem sua dubla finalidade econômica e social.

Palavras-chave: cooperativas, crédito, desafios, gestão, poupança, regulamentação. 


\section{Introducción}

El Sistema Financiero Mexicano (SFM) está integrado por diversas entidades que participan en el mercado de la intermediación financiera, entre las que se encuentran 47 bancos, 11 administradoras de fondos para el retiro, 62 operadoras de fondos de inversión y de 10 instituciones de fomento. Las que en su conjunto participan con el $87.6 \%$ del total de activos del SFM, siendo la Banca Comercial la que posee la mayor parte de los activos con un 48.6 \% (Banco de México, 2014).

Además de las entidades mencionadas, existen otras que tienen una acotada participación en el SFM y que pertenecen a un sector que ha sido identificado como de ahorro y crédito popular, donde participan las sociedades financieras populares y las cooperativas de ahorro y préstamo. Ambas son organizaciones supervisadas por la Comisión Nacional Bancaria y de Valores (CNBV), que es un organismo del gobierno responsable de otorgarles la autorización para operar y que además se encarga de su supervisión. Las figuras jurídicas citadas, cuentan con fondos de protección con lo que cubren cualquier contingencia que derive de la pérdida de los ahorros que depositen los usuarios. En su conjunto, estos segmentos de entidades participan con tan sólo con el 0.7 \% de los activos totales del SFM (Banco de México, 2014). Cabe señalar que en este porcentaje no se incluyen a las cooperativas de ahorro y préstamo que se encuentran en proceso de autorización o bien, han sido clasificadas como de nivel básico.

Son precisamente las cooperativas de nivel básico el objeto de este estudio; de las que puede decirse que se ubican en regiones geográficamente dispersas y de bajo desarrollo económico ${ }^{3}$, no cuentan con Fondos de Protección para los ahorradores, no son supervisadas por la CNBV y muestran escasa formalización en su gestión. En el contexto financiero son consideradas como pequeñas, por su limitada cobertura de servicios y bajo monto de activos. A pesar de sus limitaciones, su importancia radica en que proporcionan servicios financieros a personas que difícilmente tendrían oportunidad de acceder a productos de la banca comercial, ya sea por no ser sujetos de crédito o por la ineficiencia o desinterés de la banca para ofertar sus servicios.

3 La pobreza en México se mide a través de la ausencia de derechos sociales -rezago educativo, acceso a la salud, seguridad social, alimentación, vivienda y servicios en la misma-, así como del bienestar económico -ingreso-. En condiciones de pobreza viven 53.418.151 personas ( $43.6 \%$ de la población total), de entre ellos 9.375 .581 (7.6\%) son pobres extremos. Específicamente, en Querétaro viven 635.700 personas en condiciones de pobreza, entre los que se encuentran 59.700 personas que han sido consideradas como pobres extremos (CONEVAL, 2016), 
La relevancia de las cooperativas de ahorro y préstamo de nivel básico va más allá de cubrir necesidades de financiamiento. Por su medio se busca beneficiar no solo al asociado, sino también a sus familias y a la comunidad. Fue esta la razón por la que es significativo estudiar la problemática que persiste entre éstas, así como identificar sus retos y plantear perspectivas para superarlos.

Es así que surgió la pregunta ¿cuáles son los desafíos que deben afrontar las cooperativas de ahorro y préstamo de nivel básico en México?, cuestionamiento que sirvió de guía para el estudio. Para tal efecto se recurrió al método cualitativo, seleccionando la estrategia de estudio de caso. El desarrollo del trabajo en un primer momento retomó una aproximación teórica centrada en la economía social, para luego caracterizar la situación del sector e identificar los desafíos que deben superar tales cooperativas. Finalmente se formula una propuesta para atenderlos.

Los resultados indican que concurren diversos retos que deben ser atendidos por los dirigentes y administradores de las cooperativas estudiadas, los que en suma están relacionados con el cumplimiento de la legislación, ya que si obtienen una clasificación en D -como lo prescribe la ley-, estarán destinadas a desaparecer por considerarse que su captación representa un riesgo para los socios y por tanto será inviable su permanencia en el mercado. Asimismo, los aspectos vinculados con la gestión, la oferta de nuevos productos y la estrategia que dé continuidad a la cooperativa son retos que deben ser resueltos en el corto plazo.

\section{Aproximación teórica}

La economía social incluye novedosas y diversas formas para la organización de la participación colectiva y de carácter democrático, integrando personas que comparten problemáticas comunes originadas de las transformaciones del sistema económico dominante. Las formas jurídicas que se adoptan se manifiestan principalmente a través de organizaciones dedicadas a la producción, los servicios y el consumo, entre otras que persiguen fines económicos y sociales (Defourny, 2008).

Entre las organizaciones del sector social de la economía es la cooperativa la forma jurídica más relevante, dado que se ha incluido expresamente en legislaciones que dan cuenta de su doble finalidad social y económica. En el contexto internacional se le ha definido como "una asociación autónoma de personas que se han unido voluntariamente para hacer frente a sus necesidades y aspiraciones económicas, sociales y culturales comunes por medio de una empresa de propiedad conjunta y democráticamente controladas" (ACI, 1995, p. 1). 
Las cooperativas ponen en práctica principios y valores enarbolados por la Alianza Cooperativa Internacional, los que en distintas leyes han sido incluidos para darles carácter de obligatorios. Indudablemente estas organizaciones se gestan en realidades locales y han trascendido sus propias fronteras.

Al respecto, Lafleur (2005) apunta que la cooperativa despliega su ámbito de acción en una dinámica local arraigada a las necesidades de la comunidad, su dinámica difiere según su tamaño y el sector que atiende y sus miembros. Pero su razón de ser permanece invariable: crear un valor de uso y una riqueza colectiva por y para sus miembros, explotando de manera sostenible los recursos de la comunidad. Pero además se reconoce que, en el contexto internacional, las cooperativas contribuyen al avance de las naciones, permitiendo que sus integrantes tomen el mando de su propio desarrollo.

Algunas evidencias son presentadas por la Alianza Cooperativa Internacional (ACl, 2016). Organismo que ha dado cuenta de los beneficios e impacto a escala local y mundial de las cooperativas, lo que se demuestra a través de aproximadamente 1.000 millones de socios y la creación de 100 millones de empleos. Particularmente en el sector financiero europeo, las cooperativas emplean a casi 700.000 personas. Por su parte, la OIT (2015) afirma que los ingresos agregados de las 300 empresas cooperativas más importantes del mundo ascienden a 1.6 billones de USD, cifra equivalente al PIB de España que es la novena economía mundial. Por su parte, el Consejo Mundial de Cooperativas de Ahorro y Crédito (woccu por sus siglas en inglés) ha referido, con datos a 2014, que a través de las cooperativas financieras se atienden a 217 millones de personas, agrupadas en torno a 57.000 cooperativas de ahorro y préstamo ubicadas en 105 países de seis continentes. Las cuales poseen activos por 1.8 billones USD, otorgan préstamos por 1.2 billones USD y cuentan con 1.5 billones en aportaciones y ahorros (woccu, 2015).

A pesar de ello, la realidad que persiste en el contexto internacional no es el mismo en todas las naciones. En algunas se ha logrado un avance importante que se refleja en sus indicadores económicos, lo que podría explicarse por su grado de institucionalidad. En este sentido, diversos autores como Acemoglu, Robinson (2012) y Stiglitz (2012) consideran que la institucionalidad representada a través de la certeza que debe prevalecer en un país, permea en las organizaciones cuando existen leyes y ordenamientos que son aplicados y cumplidos. Acemoglu y Robinson (2012) consideran que las sociedades, en un contexto nacional y global, requieren sin excepción, de la existencia de instituciones que cumplan con un rol regulatorio. Es decir, con ellas prevalece la ley y el orden en una nación, por lo que la creación de leyes adecuadas contribuye al desarrollo de los países a través de las organizaciones en las que los ciudadanos actúan y llevan a cabo sus actividades. 
La institucionalidad no ha sido un tema que sea convergente con la realidad de las cooperativas de ahorro y préstamo en México, ya que han transitado por diversas circunstancias en las que ha persistido una política pública limitada en su fomento y ambigüedad en cuanto a su regulación. De acuerdo con Eguía (1982) pueden ubicarse antecedentes que se remontan a 1949 cuando el Padre Pedro Velázquez gestiona el acceso a la Universidad de San Francisco en Canadá, para que los presbíteros Carlos Talavera y Manuel Velázquez estudiaran los métodos de educación popular que se estaban desarrollando en dicho país. Durante su estancia, los sacerdotes conocieron las caisses populaires, que eran entidades fundadas por Alphonse Desjardins en los primeros años del siglo xx y que estaban dedicadas a la captación de ahorros y colocación de préstamos. Por lo que, tomando la filosofía y práctica del cooperativismo canadiense, en octubre de 1951 se funda la primera organización que fue denominada genéricamente como: caja popular.

El naciente movimiento se desarrolló bajo los lineamientos de la iglesia católica, en medio de políticas públicas y un contexto regulatorio inexistente, por lo que el reconocimiento jurídico y los lineamientos para su operación quedaron al margen de cualquier organismo público. No obstante, dichas organizaciones fueron ampliamente aceptadas por la población, principalmente en los sectores más empobrecidos, donde el crédito se convirtió en un recurso fundamental para sufragar las necesidades más apremiantes (Lara, 2011).

Es relevante explicar que las cooperativas en México han sido reconocidas en la Constitución como integrantes del sector social de la economía, junto con otras organizaciones de carácter social. No obstante, la legislación particular no incluyó la intermediación financiera como una actividad propia de las cooperativas, lo que condujo a las cajas populares a funcionar sin una legislación propia. Con el paso del tiempo se ha reconocido en las cooperativas de consumo, de producción y de ahorro y préstamo, a las figuras jurídicas previstas en la Ley General de Sociedades Cooperativas vigente.

Es precisamente la cooperativa de ahorro y préstamo el objeto de este análisis, las que en palabras de Lara, Pérez y Hurtado (2017) son organizaciones del sector social de la economía, enfocadas al mercado de la intermediación financiera, proporcionando productos como el ahorro y préstamo exclusivamente para sus socios. Tales organizaciones fundamentan sus actividades en los principios y valores que constituyen la filosofía cooperativa, y su objetivo es generar valor económico y social para los asociados, sus familias y la comunidad.

No puede ignorarse que la ausencia de reconocimiento jurídico también tuvo consecuencias negativas y que los esfuerzos por institucionalizar al sector 
de ahorro y crédito popular -en el sexenio del presidente Vicente Fox- no dio los resultados que se esperaban (Lara, Pérez y Hurtado, 2017). Puede decirse que la institucionalización fue incompleta y débil (Powell, 2001), debido a que la presión gubernamental ejercida a través de la legislación fue parcial e inconsistente, lo que tuvo su origen en las inconformidades surgidas entre los dirigentes de las cooperativas, por el contenido legal que no concordaba con las prácticas y principios propios del movimiento.

Por tanto, se reconoce que las cooperativas han venido funcionando en un contexto débilmente institucionalizado y con entidades que compiten en condiciones inequitativas, por lo que para permanecer en el mercado deben afrontar desafíos, los que en términos estratégicos deben ser reforzados por la identidad de la cooperativa. Es decir, con la práctica de los principios y valores de la cooperación (Lafleur, 2003).

\section{Metodología}

Con apoyo en la perspectiva teórica se formuló la pregunta de investigación: ¿cuáles son los desafíos que deben afrontar las cooperativas de ahorro y préstamo de nivel básico en México? El cuestionamiento fue abordado considerando el método cualitativo y la estrategia de estudio de caso. Para tal efecto se emplearon técnicas como la entrevista semiestructurada, observación directa y participante, así como observación documental a través de información de fuentes oficiales de organismos gubernamentales y de la legislación cooperativa vigente.

Para efectuar un acercamiento detallado del fenómeno, se seleccionó como estudio de caso a una cooperativa de ahorro y préstamo de nivel básico, ubicada en Peñamiller, Querétaro, México. Por lo cual fue viable acceder a información de la organización, a partir de los testimonios de los directivos, de la gerente y socios. La investigación fue diacrónica y se efectuó desde abril de 2015 a noviembre de 2016.

\section{Las cooperativas de nivel básico y el estudio de caso}

Para contextualizar la situación que prevalece entre las cooperativas de ahorro y préstamo de nivel básico, se inicia este apartado describiendo el entorno en el que despliegan su actuación. Es decir, debe comprenderse el contexto y trayectoria que han seguido, para inmediatamente detallar los aspectos relevantes de la organización estudiada. 


\section{El contexto nacional de las cooperativas de nivel básico}

El sector cooperativo de ahorro y préstamo está integrado por organizaciones clasificadas en el nivel I, II, III, IV, así como en el nivel de operación básico. Son las cooperativas de nivel básico el objeto de estudio, las que de acuerdo con el artículo 13 de la Ley para Regular las Actividades de las Sociedades Cooperativas de Ahorro y Préstamo (LRASCAP, 2009), integran activos iguales o inferiores a 2.5 millones de UDIS $^{4}$, no requieren de autorización de la CNBV, no son supervisadas por organismo alguno y no cuentan con un fondo de protección para los ahorradores. Entre los requisitos que deben cumplir para operar se encuentra que: deben estar inscritas en una Federación y entregar información financiera semestral o trimestralmente al Comité de Supervisión Auxiliar del Fondo de Protección.

La participación de las cooperativas de nivel básico en el mercado de la intermediación financiera es limitada, debido a que la legislación vigente contempla que los servicios que puede ofrecer a sus socios son exclusivamente los relacionados con el ahorro y el préstamo. Tal disposición limita el desempeño financiero de la organización, debido a que no pueden colocar sus excedentes de efectivo a través de cuentas de cheques o de inversiones, en instituciones del sistema financiero -como los bancos o casas de bolsa - lo que limita la diversificación de sus operaciones y su rentabilidad.

En lo que se refiere al tamaño del sector, el Fideicomiso del Fondo de Supervisión Auxiliar de las Sociedades Cooperativas de Ahorro y Préstamo y de Protección a sus Ahorradores (FOCOOP, 2016), reporta al 30 de noviembre un total de 765 cooperativas inscritas en el Registro Nacional Único de Sociedades Cooperativas de Ahorro y Préstamo (RENSOCAP), las que administran más de 128.000.000.000 de pesos (7.100 millones de USD) en activos e integran 7.262.024 de socios. Resulta relevante señalar que, de las 765 organizaciones registradas, sólo 152 están autorizadas por la CNBV, las que en su conjunto administran el $88 \%$ de los activos del sector e integran el $81 \%$ de los socios. En contraste, 473 cooperativas son de nivel básico, administran el $2 \%$ de los activos del sector y representan al $4 \%$ de los socios. Como puede verse este último segmento de cooperativas es el más grande en cuanto al número de cooperativas, pero el más pequeño en lo que corresponde a sus activos. Lo que da pauta para considerar que representa una importante problemática para su control, vigilancia y supervisión; dado que el organismo que debería encargarse de esta función -la CNBV - no lo lleva a cabo, dado que no existe obligación legal para ello.

4 Al 25 de junio de 2017, el valor de la UDI es de 5.759175, por lo que el monto de los activos a esa fecha es de 14.397.937.50 pesos mexicanos (SAT, 2017). Lo que equivale 798.647,51 USD al 30 de junio de 2017 (SAT, 2017 a). En lo sucesivo las cantidades expresadas en pesos se convertirán a dólares al tipo de cambio referido al 30 de junio. 
Para ilustrar la composición del sector, enseguida se presenta un análisis en el que se incluye el total de cooperativas, integración de socios y porcentaje de participación en los activos (tabla 1).

Tabla 1. Estatus de entidades bajo la LRASCAP, en el FOcOOP.

\begin{tabular}{lrrrrr}
\hline \multirow{2}{*}{ Segmentos } & \multicolumn{2}{c}{ Cooperativas } & \multicolumn{2}{c}{ Socios } & \multicolumn{2}{c}{$\%$ de activos } \\
\cline { 2 - 6 } & Número & \multicolumn{1}{c}{$\%$} & Número & \multicolumn{1}{c}{$\%$} & $\%$ \\
\hline Autorizadas & 152 & $20 \%$ & $5,881,169$ & $81 \%$ & $88 \%$ \\
\hline En proceso de autorización & 25 & $3 \%$ & 331,297 & $5 \%$ & $4 \%$ \\
\hline Nivel básico & 473 & $62 \%$ & 284,498 & $4 \%$ & $2 \%$ \\
\hline Otros estatus & 115 & $15 \%$ & 765,060 & $11 \%$ & $6 \%$ \\
\hline Total & 765 & $100 \%$ & $7 ' 262024$ & $100 \%$ & $100 \%$ \\
\hline
\end{tabular}

Fuente: FOCOOP (2016)

Como puede verse en la tabla previa, las entidades del nivel básico son importantes en cuanto a número, lo que da certeza de su amplia presencia en diferentes regiones del país. No obstante, son las de menor cobertura en activos y número de socios, aunado a que por cuestiones de carácter legal no pueden acceder al Fondo de Protección, situación que no favorece a los socios, dado que en el supuesto de quebranto no existen mecanismos de protección para los depósitos efectuados (figura 1).
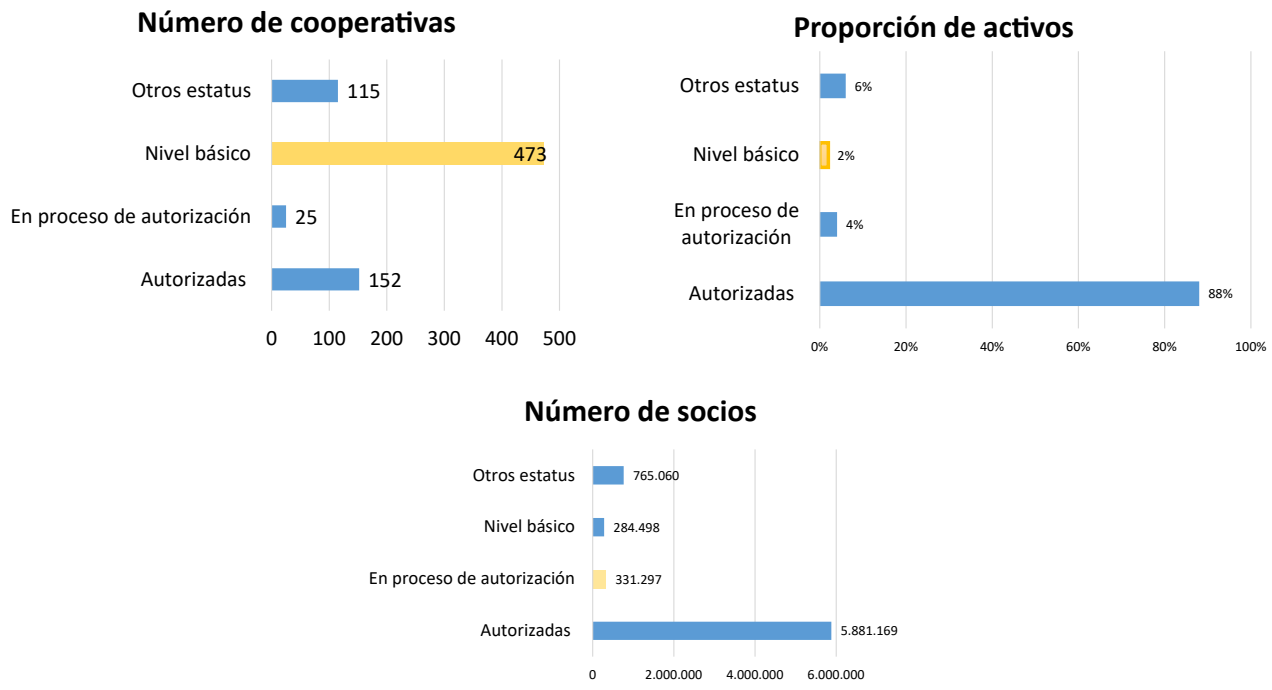

Figura 1. Cooperativas, activos y socios.

Fuente: Focoop (2016) 
En consecuencia, el segmento de cooperativas clasificadas como de nivel básico que se encuentran diseminadas por todo el país, muestra diversos obstáculos que deben ser enfrentados en el corto plazo.

\section{El caso de la cooperativa de nivel básico}

Una de las 473 cooperativas de nivel básico es la Cooperativa Morelos ${ }^{5}$ que fue fundada en el año 1965, en el anexo parroquial de la iglesia de la localidad. El principal impulsor de la iniciativa fue el Padre Romero. En sus inicios la organización fue administrada durante cuatro años por el sacerdote y los socios fundadores, quienes realizaban actividades de difusión y servicio a la comunidad. Posteriormente fue administrada en diferentes épocas por tres gerentes. En 1970 se designó el primer gerente, el señor Ramos, quien permaneció en su cargo por trece años. Luego, en 1983 se nombró al señor Rubio, quien realizó sus actividades gerenciales hasta diciembre de 2013, fecha en que falleció. La gerente que tomó el relevo inició su gestión en los primeros meses de 2014.

Desde su fundación, la organización se ha venido dedicando exclusivamente a la captación de ahorro y otorgamiento de créditos. Actualmente se ostenta como cooperativa de ahorro y préstamo, figura jurídica que fue adoptada gracias a la publicación de la Ley General de Sociedades Cooperativas en agosto de 1994. Proporciona servicios a 715 socios y 38 ahorradores menores, que viven en la comunidad y en siete localidades aledañas, o bien, que viviendo en otras regiones guarden parentesco con personas que habiten en la zona de influencia.

\section{Resultados y discusión}

Para determinar los desafíos que deben atender las organizaciones objeto de estudio, en un primer momento se retomaron estudios llevados a cabo por el Banco del Ahorro Nacional y Servicios Financieros (BANSEFI, 2015), donde se afirma que las cooperativas tienen una amplia presencia en regiones de tipo rural, dado que prestan servicios en el $37.30 \%$ de los 2034 municipios rurales del país.

Con las evidencias empíricas obtenidas y la información del sector, se delimitaron las problemáticas que evitan la participación plena del sector, en el mercado de la intermediación financiera. Enseguida se describen ocho problemáticas que han sido identificadas por BANSEFI (2015):

\footnotetext{
5 La denominación real de la cooperativa se omite por motivos de confidencialidad.
} 
1. La debilidad técnica, financiera y operativa de la organización.

2. La carencia de esquemas de profesionalización enfocados a fortalecer las habilidades gerenciales y de dirección de los responsables de la gestión.

3. La ausencia de una estructura de gobernabilidad que apoye los procesos de toma de decisiones, la transparencia y rendición de cuentas.

4. Insuficientes medidas de control interno para la protección de los recursos.

5. Escasos productos financieros enfocados a la población vulnerable y que incorporen la perspectiva de género.

6. Los elevados costos de operación.

7. Los escasos desarrollos tecnológicos que apoyen y agilicen los procesos.

8. Los altos niveles de incertidumbre para los socios de menores ingresos, dada la situación legal que impide a las cooperativas ser autorizadas y participar en el Fondo de Protección.

A los puntos mencionados deben adicionarse tres más, que están vinculados con el cumplimiento de la legislación y que son propias de las cooperativas de nivel básico:

9. La imposibilidad de participar con otras entidades financieras.

10. La ineficiencia de las cooperativas para cumplir con los requerimientos del FOCCOP.

11. El riesgo de ser clasificado en $\mathrm{D}$, de conformidad con las disposiciones legales.

Es así que con las once problemáticas identificadas se fijaron tres desafíos principales: el desafío de la legislación, el desafío de la gestión y diversificación, así como el desafío de la persistencia.

De tal manera que los problemas identificados se agruparon a partir de cada dimensión, como puede verse enseguida (figura 2): 


\section{Desafío: De la gestión y diversificación.}

- La debilidad técnica, financiera y operativa de la organización;

- La carencia de esquemas de profesionalización enfocados a fortalecer las habilidades gerenciales y de dirección de los responsables de la gestión;

- La ausencia de una estructura de gobernabilidad que apoye los procesos de toma de decisiones, la transparencia y rendición de cuentas;

- Insuficientes medidas de control interno para la protección de los recursos; y,

- Los escasos desarrollos tecnológicos que apoyen y agilicen los procesos.

\section{Desafío: De la legislación.}

- Imposibilidad de participar con otras entidades financieras;

- La ineficiencia de las cooperativas para cumplir con los requerimientos del FOCOOP; y

- Los altos niveles de incertidumbre para los socios de menores ingresos, dada la situación legal que impide a las cooperativas ser autorizadas y participar en el Fondo de Protección.

\section{Desafío: De la persistencia.}

- Escasos productos financieros enfocados a la población vulnerable y que incorporen la perspectiva de género;

- Los elevados costos de operación; y

- El riesgo de ser clasificado en $\mathrm{D}$, de conformidad con las disposiciones legales.

Figura 2. Los retos en las cooperativas de nivel básico y problemáticas a resolver. Fuente: elaboración propia

Las problemáticas citadas deben ser atendidas y superarse con la intervención de los responsables de la dirección de las cooperativas, del gobierno y de organismos de apoyo al cooperativismo -federaciones, organismos no gubernamentales, entre otras-, con lo que se podrá concebir un sector con mayor madurez y oportunidad de sobrevivir en un mercado que en su conjunto no responde a los requerimientos de los más pobres.

Con los elementos que integraron los retos se realizó el acercamiento a la realidad a través de los aspectos observables del fenómeno y así se evidenció la realidad de la cooperativa estudiada. Enseguida se abordan los tres desafíos con sus componentes.

\section{El desafío de la gestión y diversificación}

El reto que significa la gestión de una cooperativa resulta relevante e ilustra la importancia de su razón de ser; destacando su objetivo financiero, pero también social. Es decir, la práctica de los principios y valores deben estar en el centro de la estrategia y es ello lo que potencialmente fortalecería la diferenciación entre la banca y las cooperativas dedicadas a la intermediación financiera. 
Las cooperativas de nivel básico deben innovar para instrumentar nuevos productos que sean acordes a la realidad que viven los asociados, ajustándose a sus necesidades y capacidades. Por tanto, el desafío de la gestión y diversificación integra cinco problemáticas, las que están relacionadas con la eficiencia de la cooperativa en su gestión, traducidas en la capacidad de los directivos y la gerencia para tomar decisiones y responder a las necesidades de sus socios en materia financiera y de seguridad.

- La debilidad técnica, financiera y operativa de la organización.

La Cooperativa Morelos fue fundada en 1965, desde esa época funcionó otorgando servicios de préstamo y ahorro. Para su gestión se contó con el apoyo de asesores de una federación, que proporcionaba capacitación en materia de cobranza, control del efectivo, otorgamiento de créditos, formación de expedientes y contabilidad. Las prácticas aprendidas por los gerentes se fueron trasmitiendo con el paso del tiempo. A la par la federación dejó de existir y la organización siguió funcionando con los mismos métodos.

La cooperativa ha venido obteniendo recursos para su operación, a través de los rendimientos que se cobran a los socios por concepto de intereses, además de los rendimientos percibidos por inversiones de bajo riesgo en otras instituciones del sistema financiero. Este último concepto se ha dejado de obtener por la prohibición legal de participar con otras entidades del SFM. Es relevante mencionar que en la cooperativa no se paga interés al ahorro, sino que la asamblea decide que los excedentes obtenidos en un ejercicio sean repartidos en función de los movimientos en las cuentas de ahorro y previamente se separan las reservas.

Como se ha dicho, con las disposiciones contenidas en la LRASCAP (2009), la cooperativa ya no tiene acceso a abrir una cuenta de cheques en alguna institución de crédito y no puede efectuar depósitos en inversiones, lo que ha mermado drásticamente la percepción de rendimientos. Esta situación ha derivado en que la cooperativa ha presentado pérdidas en los últimos meses. Esto es grave, dado que en el corto plazo no podrá sufragar sus gastos de operación y en consecuencia no tendrá capacidad para distribuir remanentes entre sus socios, lo que apunta a la inviabilidad financiera.

Por otra parte, se estableció que la cooperativa no ha diversificado sus instrumentos de crédito y ahorro, que son las dos actividades que puede llevar a cabo por ley. Sobre el crédito, únicamente se oferta un tipo de préstamo con vencimiento mensual, a una tasa de interés normal de $2 \%$ y con interés moratorio del $3 \%$. Es importante considerar que una buena parte de los socios emigran a Estados Unidos por lo que regresan a las comunidades cada seis meses o anualmente, a su regreso pagan sus créditos con los intereses respectivos y cuando emigran gestionan otro 
crédito. Por lo anterior, el ciclo de pago es diferente al tradicionalmente establecido -mensual-, lo que ha traído como consecuencia que se presente una elevada cartera vencida que es superior al $90 \%$. Por ello, es imprescindible que las políticas crediticias se adapten a la realidad que se vive en la comunidad, ya que desde la perspectiva de los directivos y la gerente, la cartera vencida no es un problema, dado que los socios deudores han venido pagando sus créditos de acuerdo con los periodos en los que regresan a sus comunidades.

En consecuencia, los administradores deben comprender que cumplir las normas jurídicas vigentes tiene un costo, que deberá ser asumido por la cooperativa, lo que implica que se optimice la eficiencia financiera, sin perder la filosofía que los ha guiado históricamente. Esto se complica debido a que se ha cerrado una de las fuentes de recursos, es decir, ya no se obtienen los rendimientos por la colocación del dinero en inversiones de bajo riesgo, lo que ha derivado en que últimamente reporten pérdidas contables.

A efecto de atender este reto, se propone como primer paso priorizar el cumplimiento de la ley, dado que atender las disposiciones de los organismos gubernamentales genera legitimidad y confianza entre los usuarios, de tal manera que los responsables de la gestión tomen acciones encaminadas a adoptar los parámetros exigidos por el focoop en materia de contabilidad y al mismo tiempo incluir prácticas de control financiero para conocer la viabilidad económica de la cooperativa. Asimismo, en el corto plazo, deben adecuarse los productos crediticios a la realidad de sus usuarios, estableciendo plazos con vencimientos superiores a un mes.

- La carencia de esquemas de profesionalización enfocados a fortalecer las habilidades gerenciales y de dirección de los responsables de la gestión. La localidad en la que se ubica la Cooperativa Morelos, ha sido clasificada como pobre, dado que el municipio donde se localiza cuenta con un $70.1 \%$ de personas en esa situación (CONEVAL, 2010). A pesar del escaso desarrollo social y económico se ha fomentado de manera efectiva el ahorro. En general, la comunidad se encuentra rezagada del acceso a las ventajas que representaría operar en zonas urbanas. Tal situación se ve reflejada en el bajo nivel académico de la población, por lo que el padrón de socios está integrado por personas sin estudios o con nivel de educación básica - primaria y secundaria-, por tanto, entre los integrantes de los cuerpos directivos prevalecen bajos niveles de instrucción formal e informal, lo que implica que no posean formación en administración y finanzas. 
En cuanto al personal operativo, se integra únicamente por dos personas una gerente y un auxiliar-, las cuales no poseen formación o experiencia en el área financiera, por lo que su experiencia se circunscribe a las actividades que han venido realizando en la cooperativa. Cabe mencionar que la gerente se encuentra cursando una licenciatura por lo que cada fin de semana se traslada a la Ciudad de Querétaro.

Por lo señalado, es prioritaria la formación de los directivos y gerente, dado que los primeros no cuentan con las habilidades necesarias para tomar decisiones estratégicas que son vitales para la organización y para el personal es complicado capacitarse dada la carga de trabajo y las dificultades que representa viajar a lugares donde puedan obtenerla. Sin embargo, debe plantearse un programa de capacitación para directivos y personal operativo a efecto de que puedan responder a los requerimientos de los socios y de su entorno.

- La ausencia de una estructura de gobernabilidad que apoye los procesos de toma de decisiones, la transparencia y rendición de cuentas.

Las problemáticas que se han explicado antes limitan la capacidad para tomar decisiones estratégicas en favor de la cooperativa. Como se ha dicho, la Cooperativa Morelos funciona con procesos administrativos de mediados del siglo XX. Su organigrama es muy simple, se tiene una estructura jerárquica, ubicando en la cima a la asamblea, en el siguiente nivel se ubica el Consejo de Administración, a la par del Consejo de Vigilancia y el Comité de Crédito como un cuerpo directivo dependiendo del primero, en un nivel inferior y con línea de mando al Consejo de Administración se encuentra la gerencia y luego el puesto de auxiliar administrativo.

Las decisiones trascendentes se ponen a consideración de la asamblea general de socios, la que se reúne anualmente, mientras que el Consejo de Administración ejecuta las decisiones acordadas por la asamblea y autoriza ocasionalmente gastos que tengan el carácter de extraordinario. Es importante señalar que aproximadamente el $25 \%$ de los socios asiste a las asambleas, por lo que los acuerdos tomados se publican a través de carteles que se colocan en lugares visibles de la oficina.

Adicional a lo mencionado, pudo establecerse que los responsables de la dirección de la cooperativa no comprenden el significado yalcance de la gobernabilidad, gobierno corporativo o expresiones similares. Además de que no consideran necesario contar con un auditor externo ya que significaría un gasto extraordinario.

Por lo anterior, es incuestionable que, de instrumentar una estructura basada en la gobernabilidad, el gasto administrativo se incrementaría notablemente. Sin embargo, la función de control y supervisión, que ejerce el Consejo de Vigilancia, debería ser fortalecida por lo menos con la intervención de la CNBV, si esto ocurriera 
la propia comisión tendría la obligación de divulgar los estados financieros y la calificación como entidades de riesgo o con salud financiera.

- Insuficientes medidas de control interno para la protección de los recursos. En cuanto a la protección de los recursos, se detectaron fallas de control interno en el manejo del efectivo. Por ejemplo, se cuenta con una caja fuerte que se utiliza para el resguardo de los pagarés y del efectivo, sin embargo, las cantidades son muy altas, dado que ya no cuentan con cuenta de cheques y fueron cancelados los depósitos en inversiones. Tal situación representa un riesgo significativo para la organización. Además de que no están protegidos con seguros contra robo o incendio y no existen fianzas de fidelidad a favor de los responsables del control y manejo del dinero.

Es importante señalar que la operación de la cooperativa se ha basado principalmente en relaciones de confianza, por lo que no se ha considerado que existan riesgos que se deban prevenir.

- Los escasos desarrollos tecnológicos que apoyen y agilicen los procesos. La Cooperativa Morelos ha venido realizando sus procesos de manera manual, no obstante que se cuenta con sistema de cómputo e impresora, básicamente se emplea la tecnología para procesar texto, hojas de cálculo y llevar la contabilidad. Lo que resulta insuficiente para el control de los activos y pasivos de la organización.

\section{El desafío de la legislación}

A pesar del tiempo que ha transcurrido para la consolidación de una regulación acorde a las necesidades del sector, esta no se ha cristalizado, dado que las diversas organizaciones aún consideran como inadecuada la regulación vigente y las normas prudenciales que se han instrumentado. Cumplir con la legislación implica la imposición de sanciones y en casos extremos el impedimento de llevar a cabo la actividad de intermediación, lo que conduciría al cierre de la entidad. Los principales elementos que integran el desafío de la legislación se analizar a través de tres problemáticas.

- Imposibilidad de participar con otras entidades financieras.

La LRASCAP (2009), en vigor, limita expresamente la participación de las cooperativas de nivel básico con otros entes del sistema financiero. En términos prácticos esto quiere decir que no pueden efectuar inversiones de sus excedentes en bancos o casas de bolsa en instrumentos financieros de bajo riesgo, lo que representa un 
inconveniente de importancia, debido a que este tipo de entidades se localiza en lugares de alta emigración y sin servicios financieros. Por lo que, de acuerdo con las evidencias obtenidas en la Caja Morelos, los socios utilizan los servicios de la cooperativa principalmente para ahorrar los recursos que provienen de las remesas que reciben de sus familiares que se encuentran laborando en Estados Unidos.

Anteriormente la Cooperativa Morelos depositaba los recursos en instrumentos de deuda, principalmente en Certificados de la Tesorería (CETES) y con los rendimientos se sufragaba parte de los gastos de operación. Con las disposiciones legales las cooperativas se ven imposibilitadas a depositar los recursos obtenidos en instituciones del SFM, por lo que se han convertido en almacenes de moneda de curso legal -dinero en efectivo-, con el riesgo que esto representa.

Por tanto, de no modificarse la legislación, las cooperativas de nivel básico estarán destinadas a desaparecer en virtud de que no podrán enfrentar sus compromisos, como el pago de sueldos, la distribución de remanentes a los socios.

- La ineficiencia de las cooperativas para cumplir con los requerimientos del FOCOOP.

En lo que corresponde a la ineficiencia para cumplir con los requerimientos del focoop en materia de control y salud financiera. Pudo establecerse que la cooperativa objeto de estudio ha operado siguiendo los procesos tradicionales que fueron establecidos por organismos de integración ahora desparecidos - confederación y federación-, por lo que no modificaron sus criterios contables a través de normas de presentación, valuación y revelación en los estados financieros. Por ejemplo, la administración conoce el estado que guarda la cartera crediticia en cuanto a vencimiento, morosidad, tasas de interés, entre otras, pero no se realizaron movimientos contables que reflejaran tal situación, dado que hacerlo significaba un gasto extraordinario. Por tanto, de conformidad con la normatividad del FOcoop se estaría incumpliendo con la sana conducción financiera de la cooperativa, siendo este uno de los factores que ha impulsado al Focoop a calificar a la Cooperativa Morelos como una organización de riesgo.

- Los altos niveles de incertidumbre para los socios de menores ingresos, dada la situación legal que impide a las cooperativas ser autorizadas y participar en el Fondo de Protección.

En lo que corresponde a la incertidumbre que persiste en la cooperativa al no participar en el Fondo de Protección. Pudo establecerse que, de acuerdo con la información financiera, hasta hace poco tiempo la cooperativa tenía la capacidad para cubrir sus obligaciones sin menoscabo de los recursos de los socios, resultando 
un superávit que podría ser distribuido. Esto quiere decir que la cooperativa es sólida, sin embargo, participar en el Fondo de Protección daría mayor seguridad y se podrían prevenir posibles contingencias. Pero esta situación ya no es sostenible dadas las limitaciones que se han comentado y que tienen su origen en la imposibilidad para celebrar contratos con otras entidades del sistema financiero.

Es importante destacar que la cooperativa otorga a través de una empresa privada el servicio de protección a los ahorros y el préstamo en caso de fallecimiento del socio. Entregan a los beneficiarios designados el ahorro adicionado de una cantidad igual y el préstamo queda cancelado automáticamente. Este servicio tiene un costo para la cooperativa, pero se han obtenido buenos resultados ya que se han beneficiado a las familias, extinguiendo la obligación de pagar los adeudos y recibiendo el beneficio del ahorro.

\section{El desafío de la persistencia}

Para explicar este desafío se comparte la posición de Hatch (1997) quien propone que las organizaciones dependen de su medio ambiente, ya que tienen necesidad de recursos externos para funcionar y sobrevivir. En este sentido, es necesario diseñar estrategias que den rumbo a la organización a efecto de reducir la incertidumbre que se genera por los factores ambientales que se encuentran en el entorno de la cooperativa y por tanto se tenga la oportunidad de perdurar.

En este desafío fueron identificadas tres problemáticas relacionadas con los productos financieros que la cooperativa Morelos ofrece, así como con los elevados costos de operación y con el riesgo de que la organización sea clasificada en D. Tales elementos son explicados a continuación:

- Escasos productos financieros enfocados a la población vulnerable y que incorporen la perspectiva de género.

Esta problemática es común a las cooperativas de nivel básico y, particularmente, propia de la Cooperativa Morelos, quienes únicamente pueden ofertar por ley productos de ahorro y préstamo, limitando el espectro de instrumentos financieros con los que puede operar. La cooperativa percibe ahorro por el que no paga interés y otorga préstamos con vencimiento mensual, lo que deriva en que se muestre cartera vencida, razón por la que debería ofrecerse un instrumento con vencimientos a un mayor plazo, a efecto de que los socios puedan pagar en el momento que retornan 
a sus comunidades. Cabe indicar que no se han incluido productos que consideren la perspectiva de género, por lo que tanto el ahorro como el préstamo se ofrecen en condiciones iguales para hombres y mujeres.

- Los elevados costos de operación.

Es evidente que la cooperativa muestra signos de ineficiencia dado que no es capaz de operar con los recursos obtenidos por las transacciones celebradas con los socios, por lo que se requiere de los recursos generados a través de las inversiones con el SFM para reflejar resultados positivos. A este respecto, es necesario mencionar que la dinámica que se origina en la comunidad permea en la cooperativa, lo que quiere decir que, como resultado de la emigración, los jefes de familia envían cantidades de dinero que son depositadas en la cooperativa, debido a que se considera que es un lugar seguro y tienen confianza en que el dinero les será entregado en el momento que lo requieran, por lo que no solicitan préstamos o lo hacen esporádicamente. De hecho, la cartera de crédito es inferior a los depósitos en ahorro, lo que resulta en la baja captación de rendimientos derivados de los préstamos.

- $\quad$ El riesgo de ser clasificado en $D$, de conformidad con las disposiciones legales. El artículo 15 de la LRASCAP (2009) señala que las cooperativas clasificadas en el nivel básico serán objeto de evaluación durante los meses de junio y diciembre. Dicha evaluación se lleva a cabo para verificar el cumplimiento de las disposiciones relativas a la información financiera, requerimientos de capitalización y el riesgo potencial del menoscabo en el patrimonio de los socios. De tal manera que se clasificará a la cooperativa de acuerdo con cuatro categorías denominadas A, B, C y D.

Las cuatro categorías mencionadas constituyen el indicador del que depende la desaparición o continuidad de las cooperativas. Por ende, si la entidad se encuentra en la categoría A, quiere decir que el riesgo de la pérdida del patrimonio es bajo, en contraste, si se encuentra clasificada en $\mathrm{D}$, significa que deberá iniciar sus trámites para su disolución, lo que indicaría que su actividad de captación es de alto riesgo (tabla 2).

Tabla 2. Categorías y riesgos de pérdida del patrimonio.

\begin{tabular}{ccc}
\hline Categoría & $\begin{array}{c}\text { Riesgo de pérdida } \\
\text { del patrimonio }\end{array}$ & Características \\
\hline A & Bajo & $\begin{array}{l}\text { Son las cooperativas con un nivel de capitalización igual o superior } \\
\text { al } 150 \% \text { y cuya información financiera se apegue a las reglas para la } \\
\text { elaboración y presentación de los estados financieros básicos. }\end{array}$ \\
\hline
\end{tabular}




\begin{tabular}{|c|c|c|}
\hline Categoría & $\begin{array}{l}\text { Riesgo de pérdida } \\
\text { del patrimonio }\end{array}$ & Características \\
\hline B & Moderadamente bajo. & $\begin{array}{l}\text { Son las sociedades con un nivel de capitalización igual o mayor al } \\
100 \% \text { y menor al } 150 \% \text {. Se distinguen por cumplir con las reglas para la } \\
\text { preparación y presentación de los estados financieros básicos, su riesgo } \\
\text { es moderadamente bajo. }\end{array}$ \\
\hline C & $\begin{array}{l}\text { En riesgo de caer en } \\
\text { insolvencia. }\end{array}$ & $\begin{array}{l}\text { Se incluye a las sociedades que mantengan un nivel de capitalización } \\
\text { igual o mayor al } 50 \% \text { y menor al } 100 \text { \% o que teniendo un nivel de } \\
\text { capitalización superior al } 100 \% \text {, no cumplan con las reglas para la } \\
\text { formulación y presentación de los estados financieros básicos. Son } \\
\text { consideradas en riesgo de caer en estado de insolvencia si no adoptan } \\
\text { medidas correctivas para reducir el riesgo de pérdida de patrimonio de } \\
\text { sus socios. }\end{array}$ \\
\hline$D$ & $\begin{array}{l}\text { Alto. La cooperativa } \\
\text { debe abstenerse de } \\
\text { captar. }\end{array}$ & $\begin{array}{l}\text { Son las sociedades que presenten un nivel de napitalización inferior al } \\
50 \text { \%, incumplan con la presentación de sus estados financieros básicos } \\
\text {-incluye a la categoría C-. Las cooperativas en esta clasificación, } \\
\text { deberán abstenerse de captar recursos a partir del día siguiente de su } \\
\text { notificación e iniciar su disolución y cancelación. }\end{array}$ \\
\hline
\end{tabular}

Fuente: elaboración propia con base en la LRASCAP (2009).

Es significativo señalar que no obstante que la Cooperativa Morelos reporta reservas importantes, tenía una alta posibilidad de ser clasificada en $D$, debido a que no se había cumplido con los requisitos en la presentación de los estados financieros y clasificación del riesgo de su cartera crediticia, debido a que no muestra su vencimiento y morosidad.

Corresponde al Focoop efectuar la clasificación de las cooperativas de nivel básico, por lo que cuando éstas reciben el aviso sobre la clasificación asignada, se tiene la obligación de notificar a la asamblea de socios sobre el contenido de la resolución.

Si la cooperativa es clasificada en C o D, deberá convocar a asamblea en un plazo no mayor de 30 días. En este caso, estará obligada a entregar al Comité de Supervisión Auxiliar la convocatoria y el acta protocolizada de la asamblea. Es importante mencionar que, si se reciben dos clasificaciones sucesivas en $C$, pasarán a D, o bien, al incumplir con las obligaciones señaladas en la ley de la materia (LRASCAP, 2009).

Respecto a la situación que prevalece en el sector, es relevante mencionar que al 31 de diciembre se tienen trece cooperativas de nivel básico clasificadas en D.Las entidades que se encuentren en esta situación deberán realizar las acciones necesarias para su liquidación, lo que es un indicador de la desaparición paulatina de las organizaciones de este tipo. En lo que se refiere a la revisión efectuada por el Focoop, al cierre del ejercicio 2016 no han sido evaluadas 207 cooperativas de nivel básico (FOCOOP, 2016). 
Los desafíos que se han enunciado forman en su conjunto el círculo virtuoso que propiciará las acciones para asegurar no solo la sobrevivencia, sino el desarrollo y trascendencia de la cooperativa. Por lo que fijar la estrategia que fortalezca y guie las diferentes acciones en la gestión, es indispensable a efecto de continuar prestando servicios financieros a la zona en la que se ubica la Cooperativa Morelos.

\section{Propuesta para enfrentar los desafíos}

Considerando las evidencias presentadas que ponen de relieve los retos que debe enfrentar una cooperativa de nivel básico, se propone que la Cooperativa Morelos debe formular su estrategia considerando los siguientes puntos prioritarios:

1. Fortalecer el enfoque económico-social con apoyo en una gestión planificada y rigurosa; asumiendo que la rentabilidad es el elemento fundamental para el logro del objeto social y permanencia de la cooperativa.

2. Establecer un programa educativo que atienda el fortalecimiento de la identidad cooperativa. Esto es a través del conocimiento de los socios, directivosyempleados, respecto de los principiosy valores delacooperación y su aplicación práctica en la dinámica del mercado que atienden.

3. Robustecer un sistema de gobernabilidad en la cooperativa, que asegure la participación democrática de los miembros y la elección de los socios para ocupar puestos directivos. Se deben considerar las habilidades y destrezas que cada uno posea para la adecuada dirección de la organización. Adicionalmente, debe planearse la preparación de las generaciones de relevo a efecto de no perder los conocimientos y experiencia.

4. Promover la cooperación entre las cooperativas de ahorro y préstamo, apropiando o coadyuvando en la adopción o formulación de técnicas, procedimientos, metodologías, y en general experiencias que constituyan buenas prácticas en la creación de productos crediticios y de ahorro, así como sobre la adecuada operación de la organización y del sector.

5. Colaborar con otros grupos en la acción comunitaria, buscando resolver problemáticas comunes que favorezcan a los socios de la cooperativa, a sus familias y a los miembros de la población. Esto quiere decir, que no debe perderse de vista el objetivo centrado en el socio y reconocer que la creación de valor económico y social hace que la cooperativa se desarrolle y trascienda. 
6. Crear al interior de la cooperativa un sistema de representación local y nacional, con el que sea posible trasladar la experiencia de desarrollo cooperativo a otras entidades, además de aportar a las políticas públicas y regulación para el sector. Es importante divulgar las desventajas que se han venido generando con la aplicación de la legislación, particularmente las que afectan o impiden el desarrollo de las cooperativas de menor tamaño y potencial financiero.

Por último, debe señalarse que los responsables de la dirección de las cooperativas de nivel básico deben tomar conciencia que están asumiendo la responsabilidad de gestionar una empresa financiera, que requiere de una visión de futuro y de la planeación estratégica de mediano y largo plazo, a efecto de garantizar su continuidad, ya que, de no hacerlo, las organizaciones que ahora dirigen entrarán en un proceso de declinación y estarán destinadas a desaparecer.

\section{Conclusiones}

Pese a que diversas organizaciones surgieron desde mediados del siglo $x x$ y han adoptado la figura de cooperativa de ahorro y préstamo, esto no ha sido suficiente para fortalecer su grado de solidez, ya que a pesar de que la política pública del gobierno federal, enfocó sus esfuerzos a un proceso de institucionalización del sector, una gran cantidad de cooperativas del nivel básico continúan operando con las antiguas prácticas de gestión y vigilancia de las otrora cajas populares.

Se estableció que son las cooperativas estudiadas las más numerosas y las que manifiestan mayor rezago por sus características de operación y escaso potencial de recursos financieros. Su debilidad está vinculada con las normas legales que son divergentes a las que aplican a las organizaciones que se ubican en los niveles I, II, III y IV. Las diferencias estiban en que no se tiene un esquema apropiado de supervisión de sus actividades y de protección para sus ahorradores, además el acceso a otros entes financieros es nulo. Por lo que es claro que la regulación vigente en México segrega a las cooperativas de nivel básico, las cuales se encuentran en riesgo de desaparición dadas las disposiciones jurídicas vigentes.

Definitivamente son las cooperativas autorizadas por la CNBV las que han entrado en procesos de transformación en su estructura, toma de decisiones, mecanismos de control y vigilancia interna. Esto las ha conducido a modificar su dinámica a fin de cumplir con las exigencias legales; pero esto no ha ocurrido en todo 
el sector, ya que dichas mejoras se encuentran alejadas de las cooperativas del nivel básico. No obstante, se reconoce que es complejo erradicar prácticas que se han fortalecido a través de las costumbres y los hábitos, por lo que la modificación de raíz, en las cooperativas pequeñas, implica su transformación hacia nuevas formas de gestión basadas en los principios y valores de la cooperación. Lo anterior requiere de mayores esfuerzos, dado que se ha omitido la incorporación de nuevas prácticas y adecuaciones legislativas que las impulsen a buscar nuevos mecanismos para ofertar productos financieros diversificados y garantizar su rentabilidad.

En suma, los retos que deben cumplir las cooperativas de nivel básico están relacionados con la debilidad de su normatividad interna, el precario grado escolar de sus directivos y gerentes, la falta de compromiso de los socios para participar activamente en los procesos democráticos, el rezago administrativo y financiero que ha derivado de la escasa adaptación a las disposiciones legales, el desinterés para recibir educación cooperativa y la carencia de mecanismos para comprobar la rentabilidad y la creación de valor social. Las problemáticas propias de las cooperativas de nivel básico que se han planteado, deben identificarse en lo individual en cada cooperativa, para ser atendidas con la intervención de los responsables de la dirección, del gobierno y de organismos de apoyo, como las federaciones, organismos no gubernamentales, entre otras.

Finalmente, debe revalorizarse la relevancia de la propuesta cooperativa y de la necesidad de reglas institucionalizadas que regulen la correcta actuación de las organizaciones para el beneficio de la sociedad. Para ello, debe conjuntarse la voluntad y compromiso de los beneficiados con la acción cooperativa, pero también del gobierno quien es el responsable de proveer normas que conduzcan al sector por una vía institucional que dé certeza de la seguridad y protección de los recursos de los socios.

\section{Referencias}

Acemoglu, D. y Robinson, J. (2012). Por qué fracasan los países. México: Deusto, S.A. http:// mingaonline.uach.cl/pdf/racs/n26/art08.pdf

ACI. (1995). Principios y valores cooperativos. Recuperado de: https://www.aciamericas.coop/ Principios-y-Valores-Cooperativos-4456 
ACl. (2016). Hechos y cifras del cooperativismo en las Américas y el mundo. Recuperado de: https://www.aciamericas.coop/Hechos-y-cifras-del-cooperativismo-en-las-Americas-y-elmundo-44-44-44-44

Banco de México. (2014). Reporte sobre el Sistema Financiero 2014. Recuperado de: http://www.anterior.banxico.org.mx/publicaciones-y-discursos/publicaciones/informesperiodicos/reporte-sf/\%7BD65B2A12-08BF-ED51-33B6-9AECB09DED2E\%7D.pdf

BANSEFI (2015). Diagnóstico Programa Presupuestario F035 Programa de Inclusión Financiera. Recuperado de: https://www.transparenciapresupuestaria.gob.mx/work/models/PTP/Rein genieria_Gasto/imagenes/Ventanas/Ramo_6/06F035.pdf

CONEVAL (2010). Medición de la pobreza 2010, a escala municipal. Recuperado de: https://www. coneval.org.mx/Medicion/Paginas/Informacion-por-Municipio.aspx

CONEVAL (2016). Medición de la pobreza en México y en las Entidades Federativas 2016. Recuperado de: https://www.coneval.org.mx/Medicion/MP/Documents/Pobreza_16/Pobreza_2016_ CONEVAL.pdf

Defourny, J. (2008). Las empresas sociales. Recuperado de: https://emes.net/?is=257\%3E.

Eguía, V. F. (1982) Las cajas populares de Quebec. México: Confederación Mexicana de Cajas Populares.

FOCOOP. (2016). Boletín informativo. Publicación interna. https://focoop.com.mx/WebSite 16/WebForms/Boletin.aspx

Hatch, M. J. (1997). Organization Theory, Modern, Symbolic, and Postmodern Perspectives. UK: http://global.oup.com/?cc=co

Lafleur, M. (2005). Desarrollo económico y cooperativas: Un modelo de gestión alternativa. En Reflexiones Sobre Cooperativismo: México: Universidad Autónoma de Querétaro.

Lafleur, M.(2003). La formulation de stratégie à partir de l'identité coopérative. Université de Sherbrooke.

Lara, G. G. (2011) Cambio organizacional en una federación del sector financiero popular. México: Plaza y Valdés. https://www.amazon.com/CAMBIO-ORGANIZACIONAL-En-federaci\% C3\%B3n-financiero-popular/dp/6074022925 
Lara, G. G., Pérez, S. F. y Hurtado, M. J. (2017). Finanzas Populares en México. México: Fontamara. https://www.elsotano.com/libro/finanzas-populares-en-mexico_10507290

LRASCAP (2009). Ley para Regular las Actividades de las Sociedades Cooperativas de Ahorro y Préstamo. Congreso de la Unión. México: Diario Oficial de la Federación. http://www. diputados.gob.mx/LeyesBiblio/pdf/LRASCAP_280414.pdf

OIT (2015). Las cooperativas y los objetivos de desarrollo sostenible, Debate sobre el desarrollo después de 2015. Recuperado de: http://www.ilo.org/wcmsp5/groups/public/---ed_emp/--emp_ent/---coop/documents/publication/wcms_307228.pdf

Powell, W. W. (2001). Expansión del análisis institucional. En W. Powell y P. Di Maggio. El nuevo institucionalismo organizacional. México: Fondo de Cultura Económica. https:// www.academia.edu/31848895/POWELL_Y_DIMAGGIO._El_nuevo_institucionalismo_en_ el_an\%C3\%A1lisis_organizacional..pdf

SAT. (2017). Tipo de cambio del dólar de Estados Unidos.

SAT. (2017). Unidades de Inversión.

Stiglitz, J. E. (2012). El precio de la desigualdad. México: Taurus. http://depa.fquim.unam.mx/amyd/ archivero/EPreciodelaDesigualdad_27245.pdf

WOCCU (2015). Informe estadístico. Cooperativas de Ahorro y Préstamo. Recuperado de: https:// www.aciamericas.coop/Nuevo-informe-estadistico-mundial 